\title{
Effect of a Diet Rich in Interesterified, Non-Interesterified and Trans Fats on Biochemical Parameters and Oxidative Status of Balb-c Mice
}

\author{
Elinete Eliete de Lima1,2, Luiza S. E. P. W. Castro ${ }^{3}$, Valdelúcia Maria A. de S. Grinevicius ${ }^{3}$, \\ Josiane Hilbig1, Nádia S. R. S. Mota ${ }^{3}$, Rodrigo C. Zeferino ${ }^{3}$, Roberta C. da Silva ${ }^{4,5}$, \\ Iván Jachmanián ${ }^{6}$, Edson Luiz da Silva ${ }^{7}$, Rozangela C. Pedrosa ${ }^{3}$, Jane Mara Block ${ }^{*}$ (i)
}

${ }^{1}$ Laboratory of Fats and Oils, Department of Food Science and Technology, Federal University of Santa Catarina, Florianópolis, SC, Brazil

${ }^{2}$ Campus Florianópolis Continente, Federal Institute of Education, Science and Technology of Santa Catarina, Florianópolis-SC, Brazil

${ }^{3}$ Laboratory of Experimental Biochemistry, Department of Biochemistry, Federal University of Santa Catarina, Florianópolis, SC, Brazil

${ }^{4}$ Faculty of Pharmaceutical Sciences, University of São Paulo, São Paulo-SP, Brazil

${ }^{5}$ Laboratory of Lipid Research, Department of Family and Consumer Sciences, College of Agriculture and Environmental Sciences, North Carolina A \& T State University, NC, USA

${ }^{6}$ Department of Food Science and Technology, Facultad de Química, Universidad de la República, Montevideo, Uruguay ${ }^{7}$ Laboratory of Lipids, Department of Clinical Analysis, Federal University of Santa Catarina, Florianópolis-SC, Brazil

Email: elinete@ifsc.edu.br, lsepwill@gmail.com,valgrinev@gmail.com, josiane_hilbig@terra.com.br, nadiamota18@hotmail.com, rodrigocostazeferino@hotmail.com,rcsilva@ncat.edu,ijachman@fq.edu.uy, edson.silva@ufsc.br, rozangelapedrosa@gmail.com, *janeblock@gmail.com

How to cite this paper: de Lima, E.E. Castro, L.S.E.P.W., de S. Grinevicius, V.M.A., Hilbig, J., Mota, N.S.R.S., Zeferino, R.C., da Silva, R.C., Jachmanián, I., da Silva, E.L., Pedrosa, R.C. and Block, J.M. (2020) Effect of a Diet Rich in Interesterified, Non-Interesterified and Trans Fats on Biochemical Parameters and Oxidative Status of Balb-c Mice. Food and Nutrition Sciences, 11, 1032-1052

https://doi.org/10.4236/fns.2020.1111073

Received: October 3, 2020

Accepted: November 27, 2020

Published: November 30, 2020

\begin{abstract}
The aim of this study was to investigate the effects of different modified fats on the body weight, biochemical profile, and biomarkers of hepatic oxidative status in Balb- $c$ mice. The animals were divided into four groups and fed for 75 days with a normolipidic (Control Group, CG) or hiperlipidic diets $(40 \%$ $\mathrm{kcal}$ ) containing a commercial interesterified fat (IFG) rich in palmitic acid (39\%); a blend of non-interesterified fat (NIFG), with 2-fold less saturated fatty acids at the $s n-2$ position of triacylglycerols; or a partially hydrogenated vegetable oil (PHFG), source of trans fatty acid (20\%) and of linolenic acid (6\%). The mice of the IFG and NIFG presented similar results in all evaluated parameters. The serum biochemical profile and hepatic oxidative stress markers in mice of the PHFG were similar to CG, except for total cholesterol (TC) which was significantly higher $(\mathrm{p}<0.05)$ for the mice of the PHFG. The mice feed with interesterified fat (IFG) showed serum TC $(\mathrm{p}<$
\end{abstract}


Copyright $\odot 2020$ by author(s) and Scientific Research Publishing Inc. This work is licensed under the Creative Commons Attribution International License (CC BY 4.0).

http://creativecommons.org/licenses/by/4.0/
$0.01)$, non-HDL-C $(\mathrm{p}<0.05)$, glucose $(\mathrm{p}<0.05)$ and hepatic reduced glutathione values $(2.7$ fold, $\mathrm{p}<0.05)$ and glutathione reductase activity $(2.4$ fold, $\mathrm{p}<0.001)$ significantly higher when compared to the mice fed with partially hydrogenated vegetable oil (PHFG). The hydrogenated fat source of trans fatty acid (20\%) had less important metabolic effects than fats containing amounts of palmitic acid (interesterified or non-interesterified). Our results suggest that the replacement of hydrogenated fats by interesterified fats may not be such a simple solution to reduce or eliminate trans fatty acids in foods.

\section{Keywords}

Interesterified Fat, Trans Fat, Palmitic Acid, Cholesterol, Oxidative Stress

\section{Introduction}

Modified fats are used in the food industry for improving oxidative stability and achieving adequate sensory characteristics in the final product. The plasticity of fats and oils is changed by partial hydrogenation and interesterification, making them suitable for food applications [1]. In the last 100 years, most of the processed food such as crisps, biscuits, confectionery, cereal bars, snacks, ice creams, and bread, among others, have been formulated with partially hydrogenated fat. The partial hydrogenation process of oils alters the configuration of unsaturated fatty acids from cis to trans. The consumption of trans fatty acids (TFAs) has been associated with the increase of the risk of diseases such as cardiovascular disease [2] [3], type 2 diabetes mellitus [4] [5] and cancer [6] [7]. For this reason, the intake of TFAs has been discouraged in the last years, and several countries have adopted actions to reduce or eliminate trans fatty acids in processed foods. Recently, the program "Replace", an initiative of the World Health Organization (WHO) to make the world free of trans fat until 2023, has been announced [8] [9].

The interesterification has been primarily used to replace the hydrogenation by the food industry as an economically viable alternative. The process allows the production of zero-trans fats with desirable functional properties. The triacylglycerol composition of blends of fats and oil is modified by rearranging the fatty acids within and between triglyceride molecules, using chemical or enzymatic catalysis [1] [10].

The interesterified fats commonly used in the food industry contain fats that are rich in long-chain SFA, such as palmitic acid (16:0) and stearic acid (18:0) [10] [11]. A proper melt profile and solid fat content can be achieved using palm oil, which presents $50 \%$ of saturated fat in its composition [12]. In addition, unlike unmodified vegetable oils, interesterified fats have a larger amount of saturated fatty acids (SFA) at the sn-2 position of glycerol. The effect of the specific arrangement of the fatty acids on the glycerol backbone on health is not understood. There is a possibility that positional composition may affect dietary fat 
metabolism, digestibility and consequent effects on cardiovascular health [10] [11].

The role of interesterified fat on metabolism has been reported in previous studies [1] [10]. In a recent systematic review, the interesterification of palmitic or stearic acid-rich fats does not seem to affect fasting serum lipids and (apo) lipoproteins [13]. Other research suggests effects of the consumption of interesterified fat on lipoprotein metabolism, glycemic control, and serum liver enzymes [1] [14]. The nutritional and health implications of the long-term consumption of interesterified fat need to be better understood [1] [10]. In addition, most studies used fats that are not commercially relevant [10] [11]. For instance, interesterified oils containing groundnut oil with linseed oil [15], and palm oil with rice bran oil [16]. Therefore, there is need for studies that investigate the nutritional and health effects of long-term intake of commercially available interesterified fats.

The objective of this study was to investigate the effects of supplementation of 1) a commercial interesterified fat rich in SFA, mainly located at the sn-2 position of the TAG backbone; 2) a blend with the same FA composition as the Interesfied Fat (IF), but with a lower amount of SFA at position sn-2 and; 3) a partially hydrogenated vegetable oil source of TFA, on the nutritional and biochemical profile and hepatic oxidative stress markers in Balb-c mice.

\section{Materials and Methods}

\subsection{Fats}

Commercial interesterified (IF) and non-interesterified fats (NIF) were obtained from the Indústria Triângulo Alimentos Ltda (São Paulo, Brazil). The IF was produced by chemical interesterification for the bakery application. The IF and NIF presented the same fatty acid profile since they were composed of the same oils and fats (palm oil, palm stearin, and fully hydrogenated soybean oil). Partially hydrogenated fat (PHF) was purchased in a local supermarket, and it was formulated with a mixture of soybean and palm oil.

\subsection{Fatty Acid Profile of Fats}

The Fatty Acids Methyl Esters (FAMEs) were obtained using the methodology described by O'Fallon et al. [17]. Analyses were carried out by gas chromatography (GC-2014, Shimadzu, Kyoto, Japan) using a capillary column RTX 2330 (105 m $\times 0.25 \mathrm{~mm}$ ID; $0.20 \mu \mathrm{m}$ film thickness) containing 90\% biscyanopropyl and $10 \%$ phenylcyanopropyl polysiloxane (Restek ${ }^{\circledR}$, Bellefont, USA). The column flow was $1.0 \mathrm{~mL} \cdot \mathrm{min}^{-1}$ with injected volume $(1.0 \mu \mathrm{L})$ using a split ratio of 1:40. Synthetic air was the carrier gas, and nitrogen was the makeup gas. The temperature of the column injector was $250^{\circ} \mathrm{C}$. The column heating ramp started at $130^{\circ} \mathrm{C}$ and was kept for $5 \mathrm{~min}$, and then increased to $180^{\circ} \mathrm{C}$, with an increased rate of $5^{\circ} \mathrm{C} \mathrm{min}{ }^{-1}$. Afterward, the column was held at $180^{\circ} \mathrm{C}$ during $10 \mathrm{~min}$. Then, after increasing temperature from $180^{\circ} \mathrm{C}$ to $240^{\circ} \mathrm{C}$ (increase rate of 
$\left.3^{\circ} \mathrm{C} \cdot \mathrm{min}^{-1}\right)$, the column temperature was held at $240^{\circ} \mathrm{C}$ for $13 \mathrm{~min}$. The flame ionization detector (FID) temperature was kept at $260^{\circ} \mathrm{C}$. The FAMEs were identified and quantified as percentages (\%) based on their retention times and peak areas compared to the fatty acid's standards.

\subsection{Regiospecific Distribution of Fatty Acids in Triacylglycerols}

The regiospecific distribution of fatty acids was carried out according to Vlahov [18] using a Bruker Advance DPX 300 spectrometer (São Paulo, Brazil), performed with multinuclear probe $(5 \mathrm{~mm})$ operating at $30^{\circ} \mathrm{C}$ at a constant frequency $(75.8 \mathrm{MHz})$.

\subsection{Triacylglycerol Composition of Fat}

The triacylglycerol composition of the fats was determined according to Segura et al. [19] using an HPLC Shimadzu Prominence 20A (Kyoto, Japan) coupled with an evaporative light scattering detector (ELSD-LTII Shimadzu) with two serial columns (Supelcosil ${ }^{\text {tw }} \mathrm{C} 18 ; 25 \mathrm{~cm} \times 4.6 \mathrm{~mm} \times 5 \mu \mathrm{m}$ ) operating at $20^{\circ} \mathrm{C}$. Each sample $(5 \mathrm{mg})$ was firstly dissolved in acetone $(1 \mathrm{~mL})$ and then injected $(1$ $\mu \mathrm{L})$ using acetone/acetonitrile $(1: 1 ; \mathrm{v} / \mathrm{v})$ as mobile phase with a constant flow rate $\left(1 \mathrm{~mL} \cdot \mathrm{min}^{-1}\right)$. Additionally, a chloroform gradient $(0 \%$ to $20 \%)$ was applied for $60 \mathrm{~min}$. Then, this condition was kept for $20 \mathrm{~min}$. The order of elution of triacylglycerols standards and its corresponding equivalent carbon number (ECN) was used to identify each triacylglycerols peak in the sample.

\subsection{In Vivo Study}

\subsubsection{Animals and Experimental Design}

Twenty four female Balb-c mice (60 days old; $20.0 \pm 1.0$ g body weight) were household under controlled environmental conditions (photoperiod $12 \mathrm{~h}$; temperature $21^{\circ} \mathrm{C} \pm 11^{\circ} \mathrm{C}$ and air humidity $53 \% \pm 2 \%$ ). Mice were kept in plastic cages (maximum 6 animals/cage) receiving water and commercial or formulated pelleted chow ad libidum. Animal maintenance and treatments followed the protocol approved by the Ethics Committee for Animals Use (CEUA/UFSC PPOO784) and in agreement with the National Institutes of Health (NIH) Guidelines.

Animals were randomly assigned to one of four experimental groups ( $\mathrm{n}=6$ for each group): control group (CG); interesterified fat group (IFG); non-interesterified fat group (NIFG), and partially hydrogenated fat group (PHFG). The CG received commercial chow Bio Tec Rats and Mice, manufactured by Bio Base ${ }^{\bullet}$ Company (Águas Frias, Brazil), composed of ground corn, soy bran, wheat bran, degummed soy oil, mixture of vitamins, mixture of mineral salts, adsorbent additive, antifungal additive and antioxidant additive. The other groups received the same feed enriched with the specific fats (interesterified fat, non-interesterified fat, or partially hydrogenated fat). The hyperlipids and isocaloric formulations were prepared by adding proper amounts of specific fats in the standard chow. Table 1 presents the ingredients, composition (Kcal\%) and energy value of the 
Table 1. Ingredients, composition and energy value (Kcal \%) of the experimental diets: Control Group (CG); Interesterified Fat Group (IFG); Non-interesterified Fat Group (NIFG), and Partially Hydrogenated Fat Group (PHFG).

\begin{tabular}{ccccc}
\hline \multirow{2}{*}{$\begin{array}{c}\text { Ingredients } \\
\text { (g/kg of diet) }\end{array}$} & Normolipid diet & \multicolumn{3}{c}{ Hyperlipids diets } \\
\cline { 2 - 5 } & CG & IFG & NIFG & PHFG \\
\hline${\text { Commercial chow Bio Tec Rats and Mice }{ }^{1}}_{\text {Interesterified fat }{ }^{2}}$ & 1000 & 833 & 833 & 833 \\
Non-interesterified fat ${ }^{3}$ & 0 & 167 & 0 & 0 \\
Partially hydrogenated vegetable fat ${ }^{4}$ & 0 & 0 & 167 & 0 \\
$\begin{array}{c}\text { Composition (Kcal \%)/ } \\
\text { Energy value (kJ/g and kcal/g) }\end{array}$ & 0 & 0 & 0 & 167 \\
Lipids & & & & \\
Proteins & 10 & 40 & 40 & 40 \\
Carbohydrates & 24 & 15 & 15 & 15 \\
Energy & 66 & 45 & 45 & 45 \\
& $15.06 \mathrm{~kJ}$ & $22.6 \mathrm{~kJ}$ & $22.6 \mathrm{~kJ}$ & $22.6 \mathrm{~kJ}$ \\
& $(3.6 \mathrm{kcal})$ & $(5.4 \mathrm{kcal})$ & $(5.4 \mathrm{kcal})$ & $(5.4 \mathrm{kcal})$ \\
\hline
\end{tabular}

${ }^{1}$ Manufactured by Bio Base ${ }^{\oplus}$ Company (Águas Frias, Brazil), composed of ground corn, soy bean, wheat bran, degummed soy oil, mixture of vitamins, mixture of mineral salts, adsorbent additive, antifungal additive and antioxidant additive. ${ }^{2}$ Commercial interesterified fat obtained from the Indústria Triângulo Alimentos Ltda (São Paulo, Brazil), produced by chemical interesterification, for the bakery application, and composed of palm oil, palm stearin, and fully hydrogenated soybean oil. ${ }^{3}$ Blend composed of palm oil, palm stearin, and fully hydrogenated soybean oil, obtained from the Indústria Triângulo Alimentos Ltda (São Paulo, Brazil). ${ }^{4}$ Partially hydrogenated vegetable fat formulated with a mixture of soybean and palm oil. Purchased in a local supermarket.

experimental diets. The formulations were pelletized according to a previous report [20], and the pellets were frozen at $-18^{\circ} \mathrm{C}$. Small amounts of the chows were periodically thawed before feeding the mice during 75 days. Mice were weighed weekly, and food intake was estimated as the difference between the food offered and the residual food in the cages. The nutrition efficiency was expressed as a result of the rate between weight gain (g) and energy consumption (Kcal).

\subsubsection{Serum Biochemical Profile}

After 75 days of treatment, all mice received anesthesia, and blood samples were collected through a cardiac puncture after 8-h fasting. Recovered serum (3000 $\mathrm{rpm} / 10 \mathrm{~min}$ ) was used for quantifying the lipids, lipoproteins, glucose, and transaminases. Triglycerides and total cholesterol were measured using the Tinder's reaction [21] [22]. HDL-C was determined by the homogeneous direct method [23] with a commercial colorimetric kit (LABTEST ${ }^{\oplus}$, Lagoa Santa City, Brazil). The non-HDL-C levels were estimated by the difference between total and HDL-C. Serum glucose was measured with a colorimetric, enzymatic method [24] $\left(\right.$ LABTEST $\left.^{\circledast}\right)$. All measurements were performed using multiwell plate readings with TECAN Infinity $\mathrm{M} 200^{\circ}$. The activities of serum transaminases enzymes, aspartate aminotransferase (AST), and alanine aminotransferase (ALT) were measured by kinetic method at $340 \mathrm{~nm}$, using commercial kits LABTEST ${ }^{\circledR}$ [25]. 


\subsubsection{Hepatic Status Oxidative}

At the end of the treatment, the animals were euthanized by cervical dislocation. Livers were rapidly removed, kept on ice, and perfused with ice saline solution $(0.9 \% \mathrm{NaCl})$ for $5 \mathrm{~min}$. A portion of $100 \mathrm{mg}$ of liver was removed and immediately homogenized $(1: 9 \mathrm{w} / \mathrm{v})$ in $0.1 \%$ Triton X-100, $0.12 \mathrm{M} \mathrm{NaCl}, 30 \mathrm{mM}$ Na-phosphate buffer, pH 7.4. For the measurement of GSH content, TCA 12\% was used. Homogenization was carried out at $4^{\circ} \mathrm{C}$ in a Teflon piston homogenizer Tecnal ${ }^{\oplus}$ (Campinas, Brazil), followed by centrifugation at $10,000 \mathrm{~g}$ for 10 min. The supernatant was used for the measurement of antioxidant defense (superoxide dismutase, catalase, glutathione peroxidase, glutathione reductase activities, and reduced glutathione, GSH content) and also oxidative stress markers lipid peroxidation (thiobarbituric acid-reactive substances, TBARS) and protein carbonyl content.

Superoxide dismutase (SOD) activity was measured by monitoring the oxidation of adrenaline to adrenochrome, as described by Misra and Fridovich [26]. Catalase (CAT) activity was measured indirectly through the decomposition of hydrogen peroxide monitored at $240 \mathrm{~nm}$, according to Aebi [27]. Glutathione peroxidase (GPx) activity was measured at $340 \mathrm{~nm}$, through the glutathione/ $\mathrm{NADPH} /$ glutathione reductase system, by the reduction of terc-butylhydroperoxide, as described by Flohé and Günzler [28]. Glutathione reductase (GR) activity was determined through the NADPH oxidation rate measured at $340 \mathrm{~nm}$, according to Carberg and Mannervik [29]. Reduced glutathione (GSH) content was directly proportional to the reaction between dithiobisnitrobenzoic acid (DTNB) and GSH thiol groups in the liver samples. The yellowish thiolate formed was determined spectrophotometrically at $412 \mathrm{~nm}$, as described by Beutler et al. [30]. Enzyme activities and reduced GSH content results were normalized by the protein content using the Lowry method [31].

Evaluation of oxidative damage to lipids was determined through measurements of TBARS, according to Bird and Draper [32]. The oxidative damages related to protein carbonylation levels were determined spectrophotometrically at $340 \mathrm{~nm}$, as described by Levine et al. [33]. All measurements were done using multiwell plate reader (TECAN Infinity $\mathrm{M} 200^{\circ}$ ).

\subsection{Statistical Analysis}

All assays were done in triplicate, and results were expressed as mean \pm standard deviation. Data were analyzed by the one-way ANOVA test, followed by the Bonferroni test. Comparisons were made using GraphPad Prism software version 6.0 (San Diego, USA). Values of $p<0.05$ were considered statistically significant.

\section{Results}

\subsection{Fatty acid Composition, Regiospecific Distribution of Fats, and Triacylglycerol Composition of Fat}

Table 2 shows the fatty acid composition and the regiospecific distribution of 
Table 2. Fatty acid composition of fats (g/100) and regiospecific distribution of fatty acids in sn-1,3 and sn-2 positions in triacylglycerols of Interesterified Fat (IF), Non-interesterified Fat (NIF) and Partially Hydrogenated Fat (PHF).

\begin{tabular}{cccc}
\hline Fatty Acids & IF & NIF & PHF \\
\hline Lauric acid (C 12:0) & $2.05 \pm 0.21^{\mathrm{a}}$ & $1.95 \pm 0.21^{\mathrm{a}}$ & $0.20 \pm 0.00^{\mathrm{b}}$ \\
Myristic acid (C 14:0) & $1.45 \pm 0.07^{\mathrm{a}}$ & $1.25 \pm 0.07^{\mathrm{a}}$ & $0.20 \pm 0.00^{\mathrm{b}}$ \\
Palmitic acid (C 16:0) & $39.10 \pm 0.42^{\mathrm{a}}$ & $38.90 \pm 0.14^{\mathrm{a}}$ & $11.65 \pm 0.21^{\mathrm{b}}$ \\
Stearic acid (C 18:0) & $15.10 \pm 0.14^{\mathrm{a}}$ & $15.25 \pm 0.35^{\mathrm{a}}$ & $13.25 \pm 0.49^{\mathrm{b}}$ \\
Oleic acid (C18:1 n9c) & $33.2 \pm 0.71^{\mathrm{a}}$ & $33.55 \pm 0.64^{\mathrm{a}}$ & $40.70 \pm 0.14^{\mathrm{b}}$ \\
Linoleic acid (C 18:2 n6c) & $8.15 \pm 0.21^{\mathrm{a}}$ & $8.00 \pm 0.00^{\mathrm{a}}$ & $8.05 \pm 0.07^{\mathrm{a}}$ \\
Linolenic acid (C 18:3 n3c) & $0.20 \pm 0.28^{\mathrm{a}}$ & $0.20 \pm 0.28^{\mathrm{a}}$ & $5.60 \pm 0.85^{\mathrm{b}}$ \\
Elaidic acid (C18:1 n9t) & $0.10 \pm 0.14^{\mathrm{a}}$ & $0.10 \pm 0.14^{\mathrm{a}}$ & $17.00 \pm 0.57^{\mathrm{b}}$ \\
Linolelaidic acid (C 18:2 n6t) & $0.00 \pm 0.00^{\mathrm{a}}$ & $0.00 \pm 0.00^{\mathrm{a}}$ & $2.89 \pm 0.69^{\mathrm{b}}$ \\
Others & $0.65 \pm 0.78^{\mathrm{a}}$ & $0.80 \pm 0.00^{\mathrm{a}}$ & $0.46 \pm 0.08^{\mathrm{a}}$ \\
Total SFA & $57.70 \pm 0.0^{\mathrm{a}}$ & $57.35 \pm 0.49^{\mathrm{a}}$ & $25.30 \pm 0.28^{\mathrm{b}}$ \\
Total MUFA & $33.20 \pm 0.71^{\mathrm{a}}$ & $33.55 \pm 0.64^{\mathrm{a}}$ & $40.70 \pm 0.14^{\mathrm{b}}$ \\
Total PUFA & $8.35 \pm 0.07^{\mathrm{a}}$ & $8.20 \pm 0.28^{\mathrm{a}}$ & $13.65 \pm 0.92^{\mathrm{b}}$ \\
Total TFA & $0.10 \pm 0.14^{\mathrm{a}}$ & $0.10 \pm 0.14^{\mathrm{a}}$ & $19.89 \pm 1.26^{\mathrm{b}}$ \\
\hline Fatty acids position & IF & NIF & PHF \\
SFA (sn-1.3) & 59.90 & 72.60 & 41.20 \\
SFA (sn-2) & 61.20 & 28.10 & 0.00 \\
MUFA (sn-1.3) & 31.20 & 20.40 & 52.00 \\
MUFA (sn-2) & 21.30 & 50.60 & 49.10 \\
PUFA (sn-1.3) & 8.90 & 7.00 & 6.80 \\
PUFA (sn-2) & 21.30 & 50.90 \\
\hline & 17.50 & 0.00 & \\
\hline & & 0.90 & \\
\hline
\end{tabular}

SFA: saturated fatty acids; MUFA: monounsaturated fatty acids; PUFA: polyunsaturated fatty acids TFA: trans fatty acids. Mean \pm S.D. $(n=2)$. Different letters at the same row mean statistical difference between experimental groups $(\mathrm{p}<0.05)$.

fatty acids in the $s n-1,3$ and $s n-2$ positions in triacylglycerols of IF, NIF, and PHF. The IF and NIF fats presented the same fatty acid profile, which was rich in SFA (especially palmitic acid) and TFA free. IF presented a higher amount of SFA at the $s n-2$ position of triacylglycerol (2-fold) when compared to NIF. On the other hand, PHF presented a higher concentration of oleic fatty acid and $20 \%$ of TFA (mainly elaidic acid), $6 \%$ of linolenic acid, and absence of SFA at $s n-2$ position. Table 3 shows the effect of the interesterification on the triacylglycerols composition of IF and NIF fats. IF presented a lower amount of trisaturated (especially SSS) and disaturated triacylglycerols (especially PPO) and a higher amount (4-fold) of tri-unsaturated triacylglycerols (especially OOO), when compared to NIF.

\subsection{Food Intake, the Gain of Body Weight and Energy Consumption}

A significant decrease in food consumption ( $p<0.001$; Figure 1(A)) was observed 
Table 3. Triacylglycerols (TAGs) composition of the interesterified fat (IF) and non-interesterified fat (NIF).

\begin{tabular}{cccc}
\hline TAGs Structure & ECN & IF (\%) & NIF (\%) \\
\hline PPP & 48 & 4.72 & 4.30 \\
PSS & 52 & 1.64 & 2.90 \\
SSS & 54 & 0.00 & 15.20 \\
Trisaturated & & 6.36 & 22.40 \\
PPL & 46 & 8.01 & 6.10 \\
PPO & 48 & 5.73 & 31.00 \\
POS & 50 & 13.70 & 1.60 \\
SOS & 52 & 1.60 & 0.00 \\
Disaturated & & 29.04 & 38.7 \\
PLL & 44 & 1.58 & 0.00 \\
PLO & 46 & 1.51 & 0.00 \\
POO & 48 & 19.19 & 22.80 \\
SOO & 50 & 7.35 & 4.20 \\
Monosaturated & & 29.63 & 27.00 \\
LLO & 44 & 2.21 & 0.00 \\
LOO & 46 & 9.73 & 6.70 \\
OOO & 48 & 15.32 & 0.00 \\
Triunsaturated & & 27.26 & 6.70 \\
Others & & 7.71 & 5.20 \\
\hline
\end{tabular}

ECN = equivalent carbon number; O: oleic acid; L: linoleic acid; P: palmitic acid; S: stearic acid.

$$
\begin{aligned}
& \square \text { CG } \\
& \text { घ IFG } \\
& \text { NIFG } \\
& \text { PHFG }
\end{aligned}
$$

A.

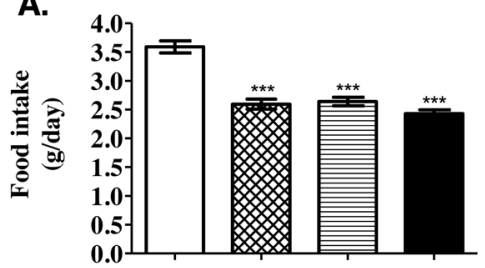

C.

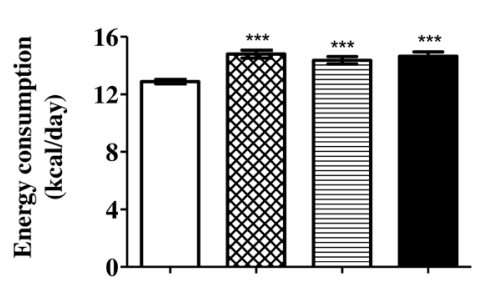

B.

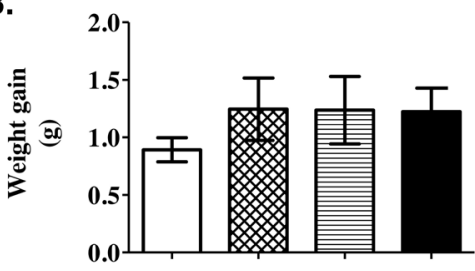

D.

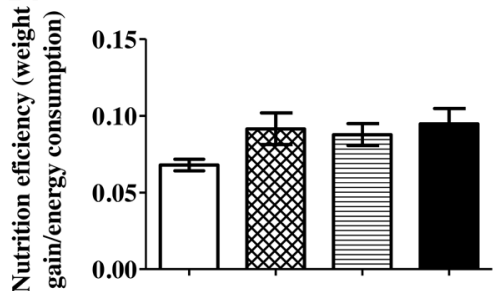

Figure 1. Effect of the consumption of interesterified fat (IFG), non-interesterified fat (NIFG), and partially hydrogenated vegetable fat (PHFG) in female Balb-c mice after 75 days. (A) Food intake (g/day); (B) Weight gain (g); (C) Energy consumption (kcal/day); and D. Nutrition efficiency (final weight - initial weight)/total energy consumption). Values are expressed as Mean \pm S.D. $(n=6) .{ }^{* * *}$ denote statistical difference $(\mathrm{p}<0.001)$ compared to the control group (CG), fed with a normolipidic diet. 
for the animals fed with the hyperlipid diets (IFG, NIFG, and PHFG) when compared to the control group (CG). The energy consumption was significantly higher for animals from the IFG, NIFG and PHFG ( $p<0.001$; Figure $1(\mathrm{C})$ ). On the other hand, it was not observed a significant difference in the body weight gain between all experimental groups (Figure 1(B)). Figure 2 shows the weight gain for the animals of the experimental groups during 75 days. The nutrition efficiency (Figure 1(D)) also did not present differences between the groups. However, the animals of the hyperlipidic groups (IFG, NIFG and PHFG) presented fat deposition in the abdomen (Figure 3).

\subsection{Serum Biochemical Profile}

The serum triglycerides were not affected by the fat present in the diet of the animals (Figure 4(A)). On the other hand, the TC (Figure 4(B)) increased in the Balb-c mice fed with the hyperlipidic diets, IFG and NIFG $(p<0.001)$, and PHFG ( $\mathrm{p}<0.05)$ when compared to CG. The increase for IFG and NIFG was
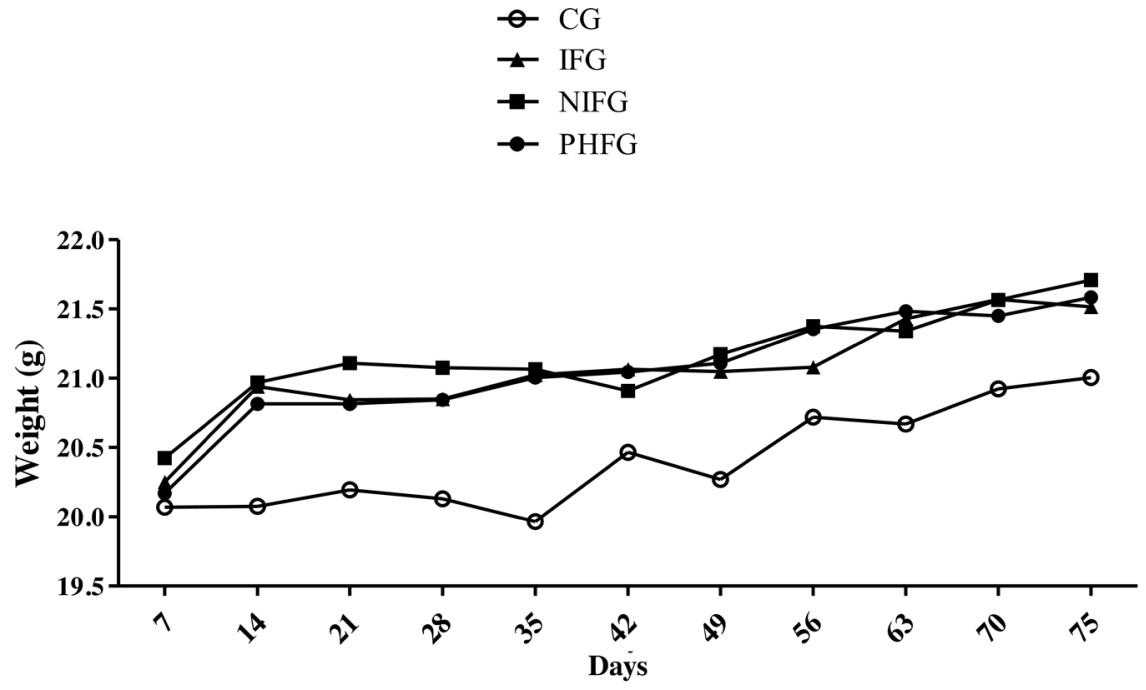

Figure 2. Progression of body weight of the experimental groups during the 75 days of treatment. Groups: Control (CG), Interesterified fat (IFG), Non-interesterified fat (NIFG) and partially hydrogenated vegetable fat (PHFG). Values are expressed as mean $(n=6)$.
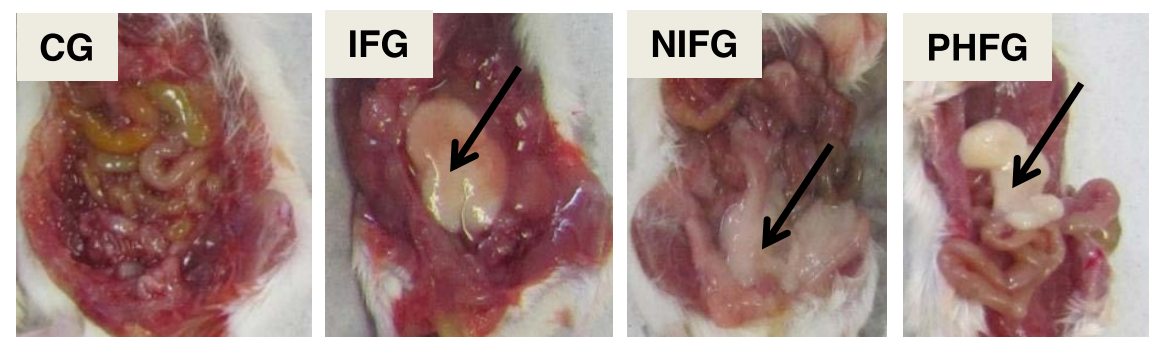

Figure 3. Abdominal fat deposition. Fat deposit (indicated by black arrow) was not observed in the Control Group (CG) fed with a normolipidic diet, but it was found in the groups which were fed with the hyperlipidic diets: Interesterified fat (IFG), Non-interesterified fat (NIFG) and partially hydrogenated vegetable fat (PHFG). 

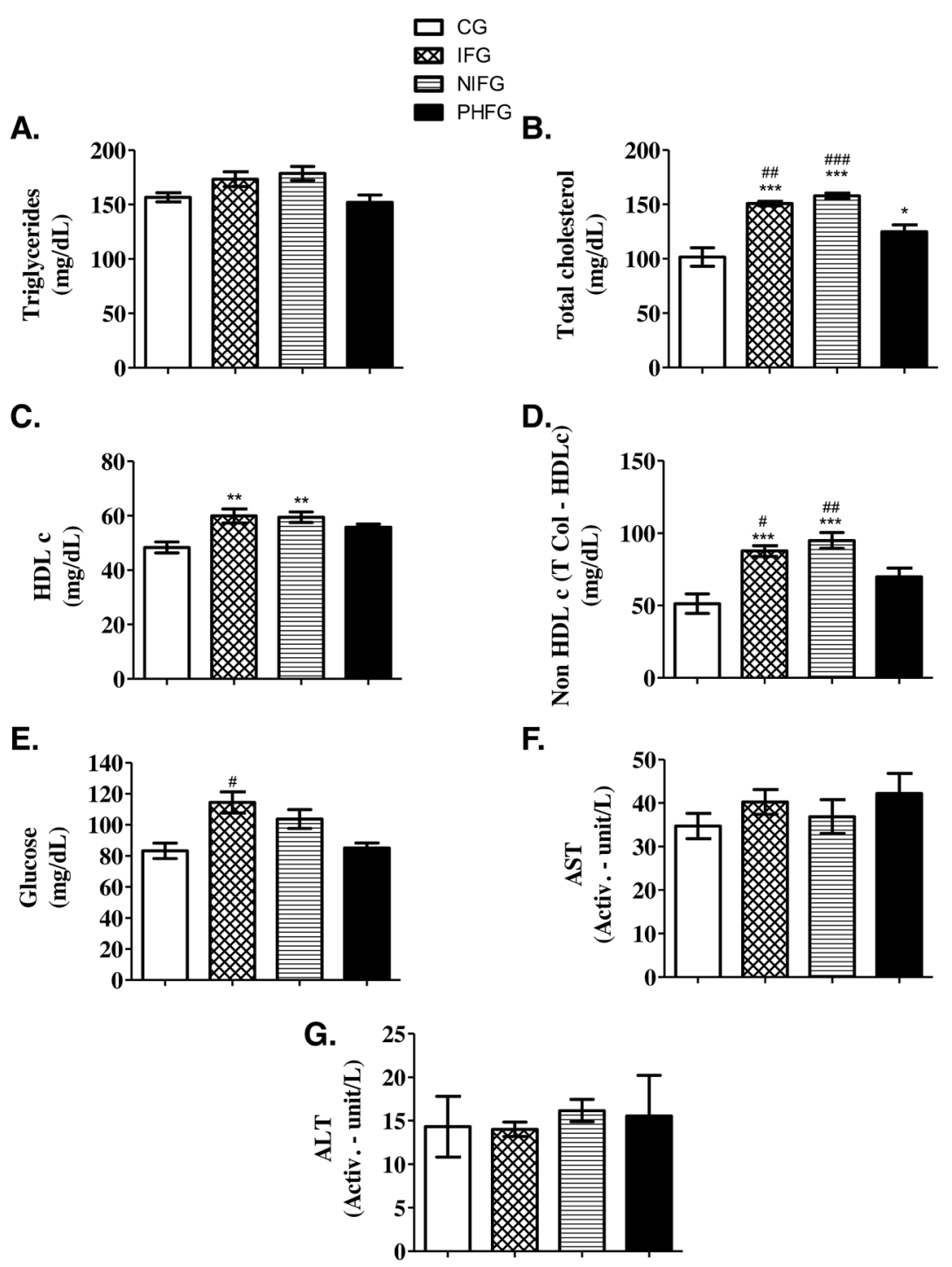

Figure 4. Effect of the consumption of interesterified fat (IFG), non-interesterified fat (NIFG), and partially hydrogenated vegetable fat (PHFG) in female Balb-c mice after 75 days, about evaluation of serum biochemical profile. Analysis of (A) Triglycerides, (B) Total cholesterol, (C) HDL-C (D) Non-HDL-C, (E) Glucose, (F) AST: aspartate amine transferase and (G) ALT: alanine amine transferase. Values are expressed as Mean \pm S.D. $(\mathrm{n}=6) .{ }^{*},{ }^{* *}$ and ${ }^{* * *}$ denote statistical difference compared to control group (CG), when $\mathrm{p}<0.05, \mathrm{p}<0.01$ and $\mathrm{p}<0.001$, respectively. ${ }^{\#}$, \# and \#\#\# denote statistical difference among groups interesterified fat (IFG), non-interesterified fat (NIFG) and partially hydrogenated vegetable fat (PHFG), when $\mathrm{p}<0.05$, $\mathrm{p}<0.01$ and $\mathrm{p}<0.001$, respectively.

more expressive and significant ( $\mathrm{p}<0.01$ and $\mathrm{p}<0.001$, respectively) when compared to PHFG. The HDL-C levels were significantly higher $(\mathrm{p}<0.01)$ in the serum of the animals fed with IF and NIF when compared with CG (Figure 4(C)). On the other hand, no significant differences were observed between IFG, NIFG, and PHFG. Figure 4(D) shows that IFG and NIFG presented a significant increase for non-HDL-C when compared to CG $(\mathrm{p}<0.001)$ and to PHFG ( $\mathrm{p}<$ $0.05, \mathrm{p}<0.001$, respectively). Figure $4(\mathrm{E})$ shows that the serum levels of glucose 
were statistically higher for IFG when compared to PHFG $(\mathrm{p}<0.05)$. The serum enzymes of hepatic function AST and ALT (Figure 4(F) and Figure 4(G), respectively), did not change between the treatments.

\subsection{Oxidative Stress and Antioxidant Defense}

The hepatic GSH content detected in the animals fed with IF and NIF was approximately 2.3 and 2.7 times higher when compared to CG and PHFG ( $p<$ 0.05). On the other hand, the results for hepatic GSH content for the animals fed with PHF were similar to the animals of the CG (Figure 5(A)).

$$
\begin{aligned}
& \square \text { CG } \\
& \square \text { IFG } \\
& \square \text { NIFG } \\
& \square \text { PHFG }
\end{aligned}
$$

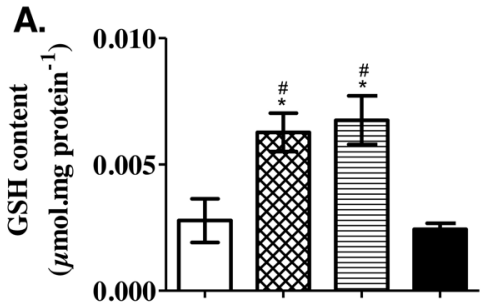

C.
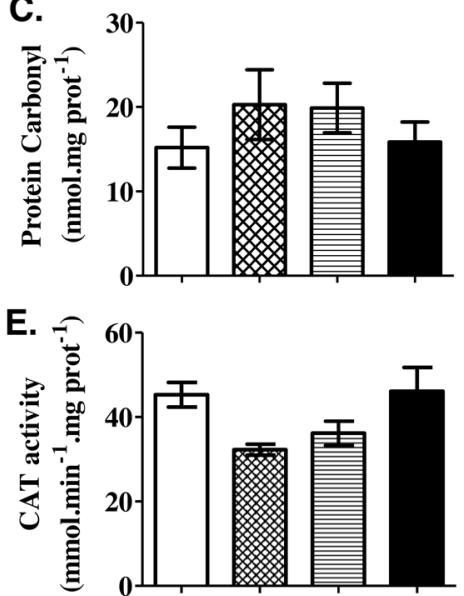

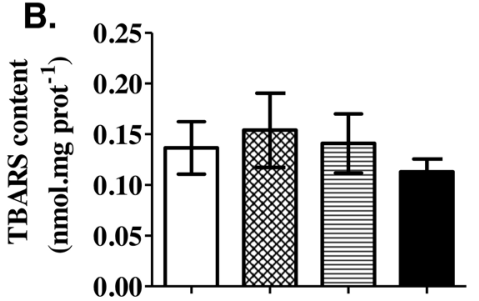

D.
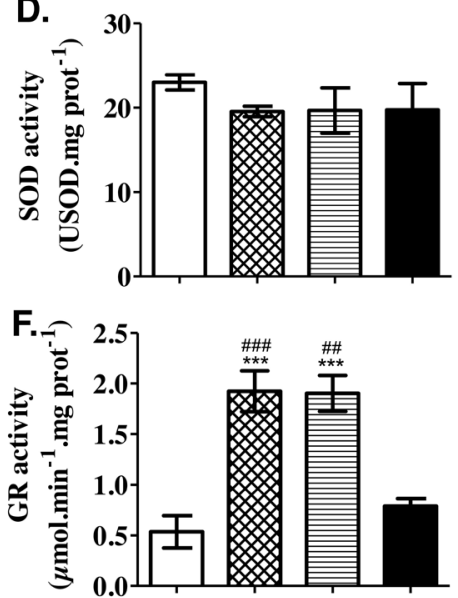

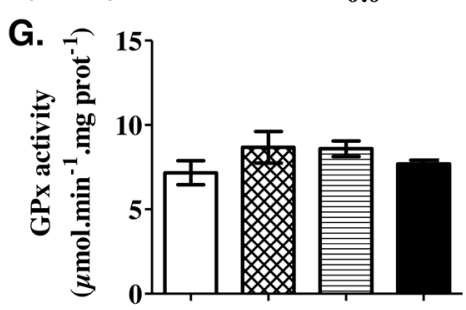

Figure 5. Evaluation of hepatic oxidative stress modulation in female Balb-c mice feed with different diets, for 75 days. Analysis of (A) GSH content, (B) TBARS content, (C) Protein Carbonyl, (D) SOD activity, (E) CAT activity, (F) GR activity and, (G) GPx activity. Values are expressed as Mean \pm S.D. $(n=6) .{ }^{\star}$ and ${ }^{\star * *}$ denote statistical difference compared to control group (CG), when $\mathrm{p}<0.05$ and $\mathrm{p}<0.001$, respectively. $\left({ }^{\#)}\right.$ and $\left({ }^{(\# \#)}\right.$ denote statistical difference among groups interesterified fat (IFG), non-interesterified fat (NIFG) and partially hydrogenated vegetable fat (PHFG), when $\mathrm{p}<0.05$ and $\mathrm{p}<0.001$, respectively. 
No differences were observed between the animals of the CG and those who received the diets studied for the oxidative markers, TBARS (Figure 5(B)), carbonyl protein values (Figure $5(\mathrm{C})$ ) and for the antioxidant enzymes SOD (Figure 5(D)), CAT (Figure 5(E)), and GPx (Figure 5(G)). In contrast, an increase of approximately 3.5 -fold in the GR activity (Figure $5(\mathrm{~F})$ ) was observed in the animals fed with IF and NIF compared to the CG. On the other hand, the GR activity in the animals fed with PHF was like those animals in the CG.

\section{Discussion}

The FA analysis indicated that IF and NIF presented around $40 \%$ of palmitic acid (C16:0). These results were expected since one of the main raw materials used in interesterification processes is palm oil and palm stearin, which presents between $40 \%-48 \%$ and $48 \%$ - $74 \%$ of palmitic acid, respectively [34]. On the other hand, the process of interesterification does not change the profile of FA of the interesterified fats [1] [10]. Vegetable oils that have not been modified typically exhibit the saturated fatty acid at the 1,3-position of the triacylglycerol [10]. In this study, was observed an increase of $100 \%$ of the amount of SFA at the sn- 2 position. Soares et al. (2009) [35] reported similar results for a 60:40 mixture of stearin and palm olein.

The amount of TFAs found in the PHF (20\%) was lower than the content reported for partially hydrogenated fats produced in the 1990s and early 2000 (from $30 \%$ to 60\%) [36] [37]. Mensink and Katan [2], in their classic study, reported an amount of $46 \%$ of TFAs in the margarine used in the experiments. The PHF also presented $6 \%$ of linolenic acid, which is an essential fatty acid. The presence of linolenic acid in the PHF indicates that this fat was produced with soybean oil, which contains $5.5 \%-9.5 \%$ of this FA in its composition [34].

During the 75 days of treatments, the animals receiving the hyperlipidic diets (IFG, NIFG, and PHFG) presented lower food intake $(\mathrm{p}<0.001)$ and higher energy consumption $(\mathrm{p}<0.001)$. However, despite the lower dietary intake, the hyperlipidic diets increased the weight gain by about $40 \%$ (although not significant), similar to previously described, for mice Balb c [38].

The weight gain and visceral adipose tissue observed for the animals fed with the interesterified fat was not significant when compared to these parameters found in the animals fed with non-interesterified and trans diets. These results may be possibly related to the time of the experiment with the hyperlipidic diet. On the other hand, Gouk et al. [39] and Afonso et al. [40] reported greater weight gain in animals fed with interesterified fat after 15 and 16 weeks of treatment, respectively. Lavrador et al. [41] reported triggered adipocytes hypertrophy in LDLr-KO mice after 16 weeks of treatment com acid palmitic interesterified. Magri et al. and Velasco et al. [42] [43] evaluated the weight gain and adiposity in C57BL/6 mice whose mothers received interesterified fat and partially hydrogenated fat during gestation and lactation. The authors concluded that the intake of interesterified and/or palm fats in this period might predispose the 
descendants to obesity in adult life. On the other hand, it was not observed for the group that received partially hydrogenated fat in the diet. Bispo et al. for C57BL-6 mice also reported that interesterified fat consumption led to deregulation in the expression of proteins involved in food intake [44].

The hyperlipidic diets used in this study did not change the serum levels of triglycerides. Controversial results have been reported in the literature for the levels of serum triglycerides after the consumption of interesterified fat. Ponnampalam et al. [45], in a study with piglets, reported an increase in the serum triglycerides after the consumption of enzymatically interesterified palm olein during 12 weeks. On the other hand, Reena; Lokeski (2007) and Sharma; Lokeski (2013) reported for Wistar rats a reduction of serum triglycerides after the consumption of interesterified fats composed of unsaturated oils during 60 days [15] [46].

The IF and NIF diets increased significantly, the serum levels of total cholesterol, HDL-C, and non-HDL-C. These results indicate that the positional distribution of the palmitic acid in positions 1 and 3 does not alter the serum lipoproteins response. Similar results were reported in experiments with humans [1] [11]. Berry [11] reported that triacylglycerols structure has no effect on either digestibility or fasting lipids. On the other hand, it has been reported for several authors that $20 \%$ of the energy in the diet as interesterified fat administered to Wistar rats, for 60 days, reduced total cholesterol and low-density lipoprotein cholesterol (LDL-C) levels [15] [16] [47] [48]. However, in these studies, blends composed of unsaturated oils, such as flaxseed, rice bran, sesame, peanut, and olive oil, were used. The fatty acid and triacylglycerol composition of these blends are very different from commercially available interesterified fats, which are rich in saturated FA, especially palmitic acid. The plasma lipid concentration of LDLr-KO mice fed for 16 weeks with interesterified fat (based on palm oil or totally hydrogenated canola oil and high-oleic sunflower oil); as $40 \%$ of the energy, was not changed [40]. However, the authors reported that interesterified fat rich in palmitic acid accelerated the development of atherosclerosis by promoting cholesterol accumulation in LDL particles and macrophage cells, activating the inflammatory process. The LDL, as well as other non-HDL-C (very low-density lipoprotein, VLDL; intermediate-density lipoprotein, IDL; lipoprotein (a), Lp(a); and chylomicron remnants), are related with the development of atherosclerosis [49]. Our results indicated that the increase in non-HDL-C in the serum of the animals who received fats rich in palmitic acid (IFG and NIFG) was higher than in animals fed with PHFG, a source of trans fat and linolenic acid. Although the trans-fat diet did not increase the non-HDL-C in the serum of the Balb-c mice, it is well-known that TFA consumption raises the non-HDL-C levels in the serum of humans [2] [3]. Other studies have indicated that palmitic acid also increased total and LDL-cholesterol concentration [50] [51], while linolenic acid may also contribute to the reduction of LDL-c [52]. Overall, these findings indicate that serum lipid response to IF, NIF, and trans-fat diet might be specie specific. Therefore, the results obtained using laboratory animals should be in- 
terpreted with caution.

In our study, no difference in serum glucose between the groups IFG and NIFG was observed. It has been reported for humans an increase the fasting plasma glucose and a decrease in plasma insulin [14] and in postprandial glucose-dependent insulinotropic polypeptide (GIP) concentrations after consumption of interesterified palm olein [53]. An increase in the levels of fasting glucose and impaired glucose tolerance was observed in Wistar rats after the consumption of interesterified soybean oil for 16 weeks. The same effect was not observed after 8 weeks [54]. In our study, a significant increase in serum glucose was observed in the animals fed with IF, compared to those fed with PHF. As reported by Miyamoto [54], the time of exposure to the diet with interesterified fat might be determinant for the increase of the plasma glucose. Lavrador et al. [41] also found no differences in glucose and insulin plasma concentrations in LDLr-KO mice fed a high-fat diet containing palmitic or interesterified palmitic fats for 16 weeks.

Hyperlipidic diets can lead to liver damage, including oxidative-based injuries [55]. In this study, after 75 days, the activities of the AST and ALT, main markers of hepatic function, were not affected. In LDLr-KO mice fed for 16 weeks which Interesterified fats enriched with palmitic or stearic acids was induced hepatic fibrosis, even without raising ALT levels [41]. Although the relationship between oxidative stress and the consumption of diets rich in TFAs is well-known [56] [57], the trans-fat diet did not change the biomarkers values of oxidative stress in the Balb-c mice. Nagaraju; Lokeski [47] reported similar results for Wistar rats fed with IF and NIF diets.

A significant increase in the GSH and GR values was observed for the diets rich in palmitic acid. It has been shown that palmitic acid presented lipotoxicity in the liver cells [58] [59]. Therefore, the increased GR activity associated with an absence of oxidative stress markers induction might be responsible for the elevation of GSH levels in IFG and NIFG, indicating a potential protection against free radical-mediated damage in the liver. It is well known that the GSH redox system is important for decreasing oxidative stress. The GSH, a radical scavenger, is converted to oxidized glutathione (GSSG), and GR continuously converts GSSG back to GSH [60].

In addition, female mice are protected against metabolic changes caused by hyperlipidic diets, while maintaining an anti-inflammatory environment in the intra-abdominal adipose tissue with expanded Treg cell population, whereas male mice can develop adipose tissue inflammation, glucose intolerance, hyperinsulinemia, and islet hypertrophy [61]. Therefore, the metabolic changes caused by hyperlipidic diets could be even more visible if the study was conducted using male mice.

\section{Conclusion}

In conclusion, the modification of the triacylglycerol structure, caused by interesterification, did not lead to different metabolic alterations. The mice that received 
the diet with interesterified fat presented similar results, as for the body weight gain, biochemical profile and biomarkers of hepatic oxidative stress, to the mice that received fat with the same fatty acid profile but with a lower (2-fold) amount of saturated fatty acids in the $s n-2$ position of triacylglycerol. However, the mice which received interesterified fat had higher serum total cholesterol, non-HDL-C and glucose concentrations, and different hepatic antioxidant response, than the group that received partially hydrogenated vegetable fat. Thus, in this study, a high-fat diet containing partially hydrogenated vegetable fat caused less important metabolic effects than fats rich in SFA and palmitic acid, interesterified, or non-interesterified. Our results suggest that the replacement of hydrogenated fats by interesterified fats may not be such a simple solution to reduce or eliminate trans fatty acids in foods, and it is necessary for further investigation in humans.

\section{Acknowledgements}

The authors are grateful to Triângulo Alimentos for the donation of interesterified fat and of blend of non-interesterified fat. J. M. Block thanks CNPq (Conselho Nacional de Desenvolvimento Científico e Tecnológico) for granting a scientific productivity fellowship (process 311070/2018-3).

\section{Funding}

This research did not receive any specific grant from funding agencies in the public, commercial, or not-for-profit sectors.

\section{Conflicts of Interest}

None of the authors had a financial or personal conflict of interest.

\section{References}

[1] Mensink, R.P., Sanders, T.A., Baer, D.J., Hayes, K.C., Howles, P.N. and Marangoni, A. (2016) The Increasing Use of Interesterified Lipids in the Food Supply and Their Effects on Health Parameters. Advances in Nutrition, 7, 719-729. https://doi.org/10.3945/an.115.009662

[2] Mensink, R.P. and Katan, M.B. (1990) Effect of Dietary Trans Fatty Acids on High-Density and Low-Density Lipoprotein Cholesterol Levels in Healthy Subjects. The New England Journal of Medicine, 323, 439-445. https://doi.org/10.1056/NEJM199008163230703

[3] Zock, P.L. and Mensink, R.P. (1996) Dietary Trans-Fatty Acids and Serum Lipoproteins in Humans. Current Opinion in Lipidology, 7, 34-37. https://doi.org/10.1097/00041433-199602000-00008

[4] Itcho, K., Yoshii, Y., Ohno, H., Oki, K., Shinohara, M., Irino, Y., Toh, R., Ishida, T., Hirata, K.I. and Yoneda, M. (2017) Association between Serum Elaidic Acid Concentration and Insulin Resistance in Two Japanese Cohorts with Different Lifestyles. Journal of Atherosclerosis and Thrombosis, 24, 1206-1214. https://doi.org/10.5551/jat.39164

[5] Liu, B., Sun, Y., Snetselaar, L.G., Sun, Q., Yang, Q., Zhang, Z., Liu, L., Hu, F.B. and 
Bao, W. (2018) Association between Plasma Trans-Fatty Acid Concentrations and Diabetes in a Nationally Representative Sample of US Adults. Journal of Diabetes, 10, 653-664. https://doi.org/10.1111/1753-0407.12652

[6] Chajès, V., Thiébaut, A.C., Rotival, M., Gauthier, E., Maillard, V., Boutron-Ruault, et al. (2008) Association between Serum Trans-Monounsaturated Fatty Acids and Breast Cancer Risk in the E3N-EPIC Study. American Journal of Epidemiology, 167, 1312-1320. https://doi.org/10.1093/aje/kwn069

[7] Hirko, K.A., Chai, B., Spiegelman, D., Campos, H., Farvid, M.S., Hankinson, S.E., et al. (2018) Erythrocyte Membrane Fatty Acids and Breast Cancer Risk: A Prospective Analysis in the Nurses' Health Study II. International Journal of Cancer, 142, 1116-1129. https://doi.org/10.1002/ijc.31133

[8] WHO World Health Organization (2018) Replace Trans Fat by 2023: An Action Package to Eliminate Industrially-Produced Trans Fat from the Global Food Supply. https://www.who.int/news/item/14-05-2018-who-plan-to-eliminate-industrially-pro duced-trans-fatty-acids-from-global-food-supply

[9] Ghebreyesus, T.A. and Frieden, T.R. (2018) REPLACE: A Roadmap to Make the World Trans Fat Free by 2023. Lancet (London, England), 391, 1978-1980. https://doi.org/10.1016/S0140-6736(18)31083-3

[10] Mills, C.E., Hall, W.L. and Berry, S. (2017) What Are Interesterified Fats and Should We Be Worried about Them in Our Diet? Nutrition Bulletin, 42, 153-158. https://doi.org/10.1111/nbu.12264

[11] Berry, S.E. (2009) Triacylglycerol Structure and Interesterification of Palmitic and Stearic Acid-Rich Fats: An Overview and Implications for Cardiovascular Disease. Nutrition Research Reviews, 22, 3-17. https://doi.org/10.1017/S0954422409369267

[12] Alfieri, A., Imperlini, E., Nigro, E., Vitucci, D., Orrù, S., Daniele, A., et al. (2017) Effects of Plant Oil Interesterified Triacylglycerols on Lipemia and Human Health. International Journal of Molecular Sciences, 19, 104. https://doi.org/10.3390/ijms19010104

[13] Van Rooijen, M.A. and Mensink, R.P. (2020) Palmitic Acid versus Stearic Acid: Effects of Interesterification and Intakes on Cardiometabolic Risk Markers-A Systematic Review. Nutrients, 12, 615. https://doi.org/10.3390/nu12030615

[14] Sundram, K., Karupaiah, T. and Hayes, K.C. (2007) Stearic Acid-Rich Interesterified Fat and Trans-Rich Fat Raise the LDL/HDL Ratio and Plasma Glucose Relative to Palm Olein in Humans. Nutrition \& Metabolism, 4, 3. https://doi.org/10.1186/1743-7075-4-3

[15] Sharma, M. and Lokesh, B.R. (2013) Modification of Serum and Tissue Lipids in Rats Fed with Blended and Interesterified Oils Containing Groundnut Oil with Linseed Oil. Journal of Food Biochemistry, 37, 220-230. https://doi.org/10.1111/j.1745-4514.2011.00627.x

[16] Reena, M.B. and Lokesh, B.R. (2012) Effect of Blending and Lipase Catalyzed Interesterification Reaction on the Cholesterol Lowering Properties of Palm Oil with Rice Bran Oil in Rats. International Journal of Food Science and Technology, 47, 203-209. https://doi.org/10.1111/j.1365-2621.2011.02827.x

[17] O'Fallon, J.V., Busboom, J.R., Nelson, M.L. and Gaskins, C.T. (2007) A Direct Method for Fatty Acid Methyl Ester Synthesis: Application to Wet Meat Tissues, Oils, and Feedstuffs. Journal of Animal Science, 85, 1511-1521. https://doi.org/10.2527/jas.2006-491

[18] Vlahov, G. (1998) Regiospecific Analysis of Natural Mixtures of Triglycerides Using Quantitative ${ }^{13} \mathrm{C}$ Nuclear Magnetic Resonance of Acyl Chain Carbonyl Carbons. 
Magnetic Resonance in Chemistry, 36, 359-362. https://doi.org/10.1002/(SICI)1097-458X(199805)36:5<359::AID-OMR274>3.0.CO; $\underline{2-Z}$

[19] Segura, N., Da Silva, R.C., Soares, F.A.S.M., Gioielli, L.A. and Jachmanián, I. (2011) Valorization of Beef Tallow by Lipase-Catalyzed Interesterification with High Oleic Sunflower Oil. JAOCS, Journal of the American Oil Chemists' Society, 88, 1945-1954. https://doi.org/10.1007/s11746-011-1876-y

[20] Gouk, S.W., Cheng, S.F., Ong, A.S. and Chuah, C.H. (2014) Stearic Acids at sn-1, 3 Positions of TAG Are More Efficient at Limiting Fat Deposition than Palmitic and Oleic Acids in C57BL/6 Mice. The British Journal of Nutrition, 111, 1174-1180. https://doi.org/10.1017/S0007114513003668

[21] Bucolo, G. and David, H. (1973) Quantitative Determination of Serum Triglycerides by the Use of Enzymes. Clinical Chemistry, 19, 476-482.

https://doi.org/10.1093/clinchem/19.5.476

[22] Allain, C.C., Poon, L.S., Chan, C.S., Richmond, W. and Fu, P.C. (1974) Enzymatic Determination of Total Serum Cholesterol. Clinical Chemistry, 20, 470-475. https://doi.org/10.1093/clinchem/20.4.470

[23] Sugiuchi, H., Uji, Y., Okabe, H., Irie, T., Uekama, K., Kayahara, N. and Miyauchi, K. (1995) Direct Measurement of High-Density Lipoprotein Cholesterol in Serum with Polyethylene Glycol-Modified Enzymes and Sulfated Alpha-Cyclodextrin. Clinical Chemistry, 41, 717-723. https://doi.org/10.1093/clinchem/41.5.717

[24] Trinder, P. (1969) Determination of Blood Glucose Using an Oxidase-Peroxidase System with a Non-Carcinogenic Chromogen. Journal of Clinical Pathology, 22, 158-161. https://doi.org/10.1136/jcp.22.2.158

[25] Rej, R. and Horder, M. (1983) Aspartate Aminotranspherase. In: Bergmeyer, H.U., Bergmeyer, J. and Grassl, M., Eds., Methods of Enzymatic Analysis, 3rd Edition, Verlag Chemie, Weinheim, 416-433.

[26] Misra, H.P. and Fridovich, I. (1972) The Role of Superoxide Anion in the Autoxidation of Epinephrine and a Simple Assay for Superoxide Dismutase. The Journal of Biological Chemistry, 247, 3170-3175

[27] Aebi, H. (1984) Catalase in Vitro. Methods in Enzymology, 105, 121-126. https://doi.org/10.1016/S0076-6879(84)05016-3

[28] Flohé, L. and Günzler, W.A. (1984) Assays of Glutathione Peroxidase. Methods in Enzymology, 105, 114-121. https://doi.org/10.1016/S0076-6879(84)05015-1

[29] Carlberg, I. and Mannervik, B. (1985) Glutathione Reductase. Methods in Enzymology, 113, 484-490. https://doi.org/10.1016/S0076-6879(85)13062-4

[30] Beutler, E., Duron, O. and Kelly, B.M. (1963) Improved Method for the Determination of Blood Glutathione. The Journal of Laboratory and Clinical Medicine, 61, 882-888.

[31] Lowry, O.H., Rosebrough, N.J., Farr, A.L. and Randall, R.J. (1951) Protein Measurement with the Folin Phenol Reagent. The Journal of Biological Chemistry, 193, 265-275.

[32] Bird, R.P. and Draper, H.H. (1984) Comparative Studies on Different Methods of Malonaldehyde Determination. Methods in Enzymology, 105, 299-305. https://doi.org/10.1016/S0076-6879(84)05038-2

[33] Levine, R.L., Garland, D., Oliver, C.N., Amici, A., Climent, I., Lenz, A.G., et al. (1990) Determination of Carbonyl Content in Oxidatively Modified Proteins. $\mathrm{Me}$ thods in Enzymology, 186, 464-478. https://doi.org/10.1016/0076-6879(90)86141-H 
[34] AOAC Association of Official Analytical Chemists (1999) Physical and Chemical Characteristics of Oils, Fats, and Waxes. US FDA, Washington DC.

[35] Soares, F.A.Z.D., Silva, R.C., Silva, K.C.G., Lourenço, M.B., Soares, D.F. and Gioielli, L.A. (2009) Effects of Chemical Interesterification on Physicochemical Properties of Blends of Palm Stearin and Palm Olein. Food Research International, 42, 1287-1294. https://doi.org/10.1016/j.foodres.2009.03.022

[36] Costales, R. and Fernández, A. (2009) Hidrogenación e Interesterificación. In: Block, J. and Barrera-Arellano, D., Eds., Temas Selectos en Aceites y Grasas, Edgard Blucher, São Paulo.

[37] Mozaffarian, D. and Stampfer, M.J. (2010) Removing Industrial Trans Fat from Foods. BMJ (Clinical Research ed.), 340, c1826. https://doi.org/10.1136/bmj.c1826

[38] Nishikawa, S., Sugimoto, J., Okada, M., Sakairi, T. and Takagi, S. (2012) Gene Expression in Livers of BALB/C and C57BL/6J Mice Fed a High-Fat Diet. Toxicologic Pathology, 40, 71-82. https://doi.org/10.1177/0192623311422078

[39] Gouk, S.W., Cheng, S.F., Mok, J.S., Ong, A.S. and Chuah, C.H. (2013) Long-Chain SFA at the sn-1,3 Positions of TAG Reduce Body Fat Deposition in C57BL/6 Mice. The British Journal of Nutrition, 110, 1987-1995. https://doi.org/10.1017/S0007114513001475

[40] Afonso, M.S., Lavrador, M.S., Koike, M.K., Cintra, D.E., Ferreira, F.D., Nunes, V.S., et al. (2016) Dietary Interesterified Fat Enriched with Palmitic Acid Induces Atherosclerosis by Impairing Macrophage Cholesterol Efflux and Eliciting Inflammation. The Journal of Nutritional Biochemistry, 32, 91-100.

https://doi.org/10.1016/j.jnutbio.2016.01.005

[41] Lavrador, M., Afonso, M.S., Cintra, D.E., Koike, M., Nunes, V.S., Demasi, M., et al. (2019) Interesterified Fats Induce Deleterious Effects on Adipose Tissue and Liver in LDLr-KO Mice. Nutrients, 11, 466. https://doi.org/10.3390/nu11020466

[42] Magri, T.P., Fernandes, F.S., Souza, A.S., Langhi, L.G., Barboza, T., Misan, V., Mucci, et al. (2015) Interesterified Fat or Palm Oil as Substitutes for Partially Hydrogenated Fat in Maternal Diet Can Predispose Obesity in Adult Male Offspring. Clinical Nutrition (Edinburgh, Scotland), 34, 904-910.

https://doi.org/10.1016/j.clnu.2014.09.014

[43] De Velasco, P., Fernandes, F., Mucci, D., Santos, R., Magri, T., Misan, V. and Tavares do Carmo, M.d.G. (2015) Interesterified Fat or Palm Oil as Substitutes for Trans Fat in Maternal Diet Can Predispose Obesity and Inflammation in Adult Male Offspring. The FASEB Journal, 29, 754.

[44] Bispo, K.P., de Oliveira Rodrigues, L., da Silva Soares de Souza, É., Mucci, D., Tavares do Carmo, M.d., de Albuquerque, K.T. and de Carvalho Sardinha, F.L. (2015) Trans and Interesterified Fat and Palm Oil during the Pregnancy and Lactation Period Inhibit the Central Anorexigenic Action of Insulin in Adult Male Rat Offspring. The Journal of Physiological Sciences, 65, 131-138. https://doi.org/10.1007/s12576-014-0351-6

[45] Ponnampalam, E.N., Lewandowski, P., Nesaratnam, K., Dunshea, F.R. and Gill, H. (2011) Differential Effects of Natural Palm Oil, Chemically- and Enzymatically-Modified Palm Oil on Weight Gain, Blood Lipid Metabolites and Fat Deposition in a Pediatric Pig Model. Nutrition Journal, 10, 53.

https://doi.org/10.1186/1475-2891-10-53

[46] Reena, M.B. and Lokesh, B.R. (2007) Hypolipidemic Effect of Oils with Balanced Amounts of Fatty Acids Obtained by Blending and Interesterification of Coconut Oil with Rice Bran Oil or Sesame Oil. Journal of Agricultural and Food Chemistry, 
55, 10461-10469. https://doi.org/10.1021/jf0718042

[47] Nagaraju, A. and Lokesh, B.R. (2007) Interesterified Coconut Oil Blends with Groundnut Oil or Olive Oil Exhibit Greater Hypocholesterolemic Effects Compared with Their Respective Physical Blends in Rats. Nutrition Research, 27, 580-586. https://doi.org/10.1016/j.nutres.2007.06.007

[48] Reena, M.B., Gowda, L.R. and Lokesh, B.R. (2011) Enhanced Hypocholesterolemic Effects of Interesterified Oils Are Mediated by Upregulating LDL Receptor and Cholesterol 7- $\alpha$-Hydroxylase Gene Expression in Rats. The Journal of Nutrition, 141, 24-30. https://doi.org/10.3945/jn.110.127027

[49] Blaha, M.J., Blumenthal, R.S., Brinton, E.A., Jacobson, T.A. and National Lipid Association Taskforce on Non-HDL Cholesterol (2008) The Importance of non-HDL Cholesterol Reporting in Lipid Management. Journal of Clinical Lipidology, 2, 267-273. https://doi.org/10.1016/j.jacl.2008.06.013

[50] Mensink, R.P., Zock, P.L., Kester, A.D. and Katan, M.B. (2003) Effects of Dietary Fatty Acids and Carbohydrates on the Ratio of Serum Total to HDL Cholesterol and on Serum Lipids and Apolipoproteins: A Meta-Analysis of 60 Controlled Trials. The American Journal of Clinical Nutrition, 77, 1146-1155.

https://doi.org/10.1093/ajcn/77.5.1146

[51] Sun, Y., Neelakantan, N., Wu, Y., Lote-Oke, R., Pan, A. and van Dam, R.M. (2015) Palm Oil Consumption Increases LDL Cholesterol Compared with Vegetable Oils Low in Saturated Fat in a Meta-Analysis of Clinical Trials. The Journal of Nutrition, 145, 1549-1558. https://doi.org/10.3945/jn.115.210575

[52] Rodriguez-Leyva, D., Dupasquier, C.M., McCullough, R. and Pierce, G.N. (2010) The Cardiovascular Effects of Flaxseed and Its Omega-3 Fatty Acid, Alpha-Linolenic Acid. The Canadian Journal of Cardiology, 26, 489-496. https://doi.org/10.1016/S0828-282X(10)70455-4

[53] Filippou, A., Teng, K.-T., Berry, S.E. and Sanders, T.A.B. (2014) Palmitic Acid in the sn-2 Position of Dietary Triacylglycerols Does Not Affect Insulin Secretion or Glucose Homeostasis in Healthy Men and Women. European Journal of Clinical Nutrition, 68, 1036-1041. https://doi.org/10.1038/ejcn.2014.141

[54] Miyamoto, J.É., Ferraz, A.C.G., Portovedo, M., Reginato, A., Stahl, M.A., Ignacio-Souza, L.M., et al (2018) Interesterified Soybean Oil Promotes Weight Gain, Impaired Glucose Tolerance and Increased Liver Cellular Stress Markers. The Journal of Nutritional Biochemistry, 59, 153-159.

https://doi.org/10.1016/j.jnutbio.2018.05.014

[55] Masarone, M., Rosato, V., Dallio, M., Gravina, A.G., Aglitti, A., Loguercio, C., et al (2018) Role of Oxidative Stress in Pathophysiology of Nonalcoholic Fatty Liver Disease. Oxidative Medicine and Cellular Longevity, 2018, Article ID: 9547613. https://doi.org/10.1155/2018/9547613

[56] Monguchi, T., Hara, T., Hasokawa, M., Nakajima, H., Mori, K., Toh, R., Irino, Y., Ishida, T., Hirata, K.I. and Shinohara, M. (2017) Excessive Intake of Trans Fatty Acid Accelerates Atherosclerosis through Promoting Inflammation and Oxidative Stress in a Mouse Model of Hyperlipidemia. Journal of Cardiology, 70, 121-127. https://doi.org/10.1016/j.jjcc.2016.12.012

[57] Dhibi, M., Brahmi, F., Mnari, A., Houas, Z., Chargui, I., Bchir, L., Gazzah, N., Alsaif, M.A. and Hammami, M. (2011) The Intake of High Fat Diet with Different Trans Fatty Acid Levels Differentially Induces Oxidative Stress and Non Alcoholic Fatty Liver Disease (NAFLD) in Rats. Nutrition and Metabolism, 8, 65. https://doi.org/10.1186/1743-7075-8-65 
[58] Zhang, Y., Yang, X., Shi, H., Dong, L. and Bai, J. (2011) Effect of $\alpha$-Linolenic Acid on Endoplasmic Reticulum Stress-Mediated Apoptosis of Palmitic Acid Lipotoxicity in Primary Rat Hepatocytes. Lipids in Health and Disease, 10, 122. https://doi.org/10.1186/1476-511X-10-122

[59] Guo, W., Wong, S., Xie, W., Lei, T. and Luo, Z. (2007) Palmitate Modulates Intracellular Signaling, Induces Endoplasmic Reticulum Stress, and Causes Apoptosis in Mouse 3T3-L1 and Rat Primary Preadipocytes. American Journal of Physiology. Endocrinology and Metabolism, 293, E576-E586.

https://doi.org/10.1152/ajpendo.00523.2006

[60] Yao, J.K., Leonard, S. and Reddy, R. (2006) Altered Glutathione Redox State in Schizophrenia. Disease Markers, 22, 83-93. https://doi.org/10.1155/2006/248387

[61] Pettersson, U.S., Waldén, T.B., Carlsson, P.O., Jansson, L. and Phillipson, M. (2012) Female Mice Are Protected against High-Fat Diet Induced Metabolic Syndrome and Increase the Regulatory T Cell Population in Adipose Tissue. PLoS One, 7, e46057. https://doi.org/10.1371/journal.pone.0046057 


\section{Abbreviations}

CG, control group;

IFG, interesterified fat group;

NIFG, non-interesterified group;

PHFG, partially hydrogenated vegetable fat group;

TC, total cholesterol;

Non-HDL-C, non-HDL cholesterol;

HDL, high density lipoproteins;

TFAs, trans fatty acids;

WHO, World Health Organization;

SFA, saturated fatty acids;

FA, fatty acids;

IF, interesfied fat;

NIF, non-interesterified;

PHF, partially hydrogenated vegetable fat;

FID, flame ionization detector;

FAMEs, fatty acids methyl esters;

ECN, equivalent carbon number;

NIH, National Institutes of Health;

AST, aspartate aminotransferase;

ALT, alanine aminotransferase;

SOD, superoxide dismutase;

CAT, catalase;

$\mathrm{GPx}$, glutathione peroxidase;

GR, glutathione reductase;

GSH, reduced glutathione;

DTNB, dithiobisnitrobenzoic acid;

TBARS, thiobarbituric acid-reactive substances

TAGs, triacylglycerols;

SSS, trisaturated triacylglycerols (S, stearic acid);

PPO, disaturated triacylglycerols (P, palmitic acid and O, oleic acid)

OOO, tri-unsaturated triacylglycerols (O, oleic acid);

LDL-C, low-density lipoprotein cholesterol;

VLDL, very low-density lipoprotein;

IDL, intermediate-density lipoprotein;

$\mathrm{Lp}(\mathrm{a})$, lipoprotein (a);

GIP, insulinotropic polypeptide;

GSSG, oxidized glutathione. 